\title{
The Benefits of Participating In Sport Activities for Socio- Economic Transformation: A Case Study of A2 and A1 Farmers in Wedza District, Zimbabwe
}

\author{
Abisha Mugari (Lecturer) \\ Zimbabwe Open University \\ Department of Health Sciences \\ Mashonaland East Region, Marondera \\ abishamugari@gmail.com
}

\author{
Richard Bukaliya (Professor) \\ Zimbabwe Open University \\ Department of Teacher Development \\ Mashonaland East Region, Marondera \\ bukaliar@gmail.com
}

\begin{abstract}
This study aimed at assessing and ascertaining the A2 and A1 resettled farmers' appreciation of the benefits accrued when engaging in sport life-style than a sedentary one with the view that once they participate in sports they are free from chronic diseases and actively contribute to the socio-economic transformation blueprint (ZIMASSET) through their farming activities. The primary concern of this study was premised on the common traditional belief and practice that farmers should dedicate their energy and time to food production, while sport engagement in farms is regarded as sheer waste of precious time yet researchers have found out that "sport exercise is medicine". A case study was deemed an appropriate design focusing on 6 farms with an estimated population of 1500 people in Wedza District. A sample of 75 farmers was ecologically, stratified and purposively selected as research participants to be interviewed, observed and answered some open-ended questionnaires, since the study was a qualitative one. Results indicated that the majority of farmers recognised the social benefits of being sport active, but were unaware of economic benefits and which sport development strategies to employ so as to transform their economic life style in the farming areas. The study recommended change to attitudes, engagement of political leadership, establishing of social sport clubs and resuscitation of former white farmers' sport facilities.
\end{abstract}

Keywords: Sport Activities, Socio-economic Transformation, A2 and A1 Farmers, Sedentary life

\section{INTRODUCTION}

Sport is one of the most cross-cutting of all development tools. Researchers have it that sport is increasingly being used to promote health and prevent diseases, strengthen child and youth development and education, foster social inclusion of persons with disabilities, promote employment and economic development. The power of sport has spread tentacles to enhance the achievements of international and local aspirations, for instance, the United Nations Millennium Development Goals, the International Declaration of Human Rights and the most recent Zimbabwean ZIMASSET policy.

Sport has for time immemorial been viewed as a lifestyle for leisure and pastime for the rich to enjoy, and fitness for defence purposes. The schools of thought that propound that exercise is medicine, sport has the power to unite communities, sport can be a tool for development and peace building, were absent in the annals of countries' economic developments strategies. However, the government of Zimbabwe has come up with its economic blue print code named ZIMASSET in 2014 in an attempt to revamp its economic development that calls for each and every community sector to participate so as to see the success of this economic policy. In the last decade, Zimbabwe has embarked upon Land Reform Programme which has seen its large population occupying white occupied farms with the aim to empower the indigenous black farmers under model A1 and A2 farms.

The major focus for these newly settled farmers is/was to produce food to sell and feed the nation. Zimbabwe once better known as the breadbasket of Southern Africa, these new farmers become more focused on regaining this status, and have never considered any other different life style like engaging themselves into leisure and sport activities as that life style could be taken as waste of valuable farming time. Evidence was that most of the football, cricket, polo and golf pitches left by white commercial farmers were turned and annexed as crop fields. Absence of sport clubs in these models of farming speaks much of the fact that sport could be regarded by these farmers as trivial and waste 
of production time, yet scientific researches by Brown (2010), Hoye et al (2009) have found that sedentary life-style exposes humans to numerous chronic diseases and other ailments that could wipe out the same farmers whom the Zimbabwe government expects to contribute to the sustainability of the Zimbabwe-economic agenda. Sedentary life style in this context refers to that culture of not participating in any competitive sport, and this is prevalent in these two models of farming in Zimbabwe, unlike those people left in former tribal trust lands who have pitches at schools and community centres where they can exercise their bodies during sport tournaments.

It is against this background that this study aimed at assessing and ascertaining the level of appreciation by these newly settled farmers of the values of sport to their socio-economic development.

\section{Statement of the Problem}

The farming population's main focus is on producing high yields, leaving them without any sport and recreation time as this could be taken as time wasting since different crop varieties need their attention throughout the year. That pressure to meet farming targets has left both A1 and A2 model farmers barely with any time to participate in sport and recreation life style. It is therefore, a concern to researchers of this study to find out the appreciation level of these farmers and come up with strategies to motivate farmers to engage them to participate in sport and recreation so as to keep them healthy and fit so that they keep on contributing to sustainable development of Zimbabwean economy.

\section{RESEARCH QUESTIONS}

i. What socio-economic benefits do new farmers gain by participating in sport and recreation?

ii. How sedentary life-style affect A1 and A2 farmers?

iii. What perceptions do farmers have on sport and recreation participation?

iv. Which strategies are most appropriate for farmers to participate in sport and recreation in farms?

\section{LITERATURE REVIEW}

\subsection{Socio-Economic Benefits}

Contemporary studies have concluded that sport and recreation potentially have a significant impact on a country's economy and once the economy of a country is positively stable, its population eventually gains several benefits in their social and economic life, (Ashton, Gerrard and Hudson, 2003).

\subsubsection{Health Issues}

According to Mugari and Masocha (2015), young ladies who participate in sports reduce their chance of getting breast cancer by $60 \%$. This could be an advantage to most female farmers and their households if knowledge is made known to these farmers, as according to World Health Organization (WHO) (2014) a sick population cannot generate the productivity needed to maintain the acceleration of its economy. A healthy and fit farming population could maintain and increase the agricultural yields. As farmers who grow large varieties of crops and keep animals for food, there is much risk of unguided nutritional feeding, which might result into the dangers of obesity. UNICEF (2014) through Ministry of Health and Child Care (2014), observed that Zimbabweans have adopted more and more of the western cultures, diets and mode of operation as changes in farming technology has introduced farmers who used to be exercising as the labour force, to a slower activity driven life with less and less physical demand on the body and too much time to feast on meals that are bad for the diets.

These schools of thought culminate into saying there are some preventive measures that must be brought into practice to reduce health diseases attacking the productive generation which is expected to satisfy the pillars of Zimbabwe Agenda for Sustainable Socio-Economic Transformation (ZIMASSET). Doing sport is the cheapest diseases prevention that even a poor farmer can embark upon as compared to huge amounts of money one would spend on hospital bills if attacked by chronic diseases. Once a farming population is under the siege of chronic diseases, instead of channelling their financial resources towards buying crop chemicals, hiring labour and farm machinery to contribute substantially to ZIMASSET, they redirect funds to hospital bills. Therefore, it is imperative for sport and recreation administrators to introduce sport gyms, aerobic clubs, soccer and netball teams in these A1 and A2 model farming communities so that farmers participate during their past time. 


\subsubsection{Economic Issues}

The economic benefits accrued from participating in sport and recreational activities among farmers might be obscured to the public by the complex reality of the truth. For instance, it is imperative for communities to meet and share farming ideas, and researches e.g by Luiz and Fadal (2010) has concluded that sport is tied intimately to issues of national pride and has the potential to reduce deep divides in fragmented societies. What it means is that as communities in these farming models have little time to spare as they are pinned to farming competitions, sport tournaments would gather them together as one people, and obviously sharing of farming expertise is done as they start to know each other by his/her farming status. The culture of sharing knowledge improves these families' relations and finally improves their yields and their economic development.

Food Security and Nutrition is one of Zimbabwe's economic blue-print, ZIMASSET, strategic cluster, therefore, once farmers cross-pollinate farming expertise by gathering together and knowing each other during sport and recreational activities like soccer and netball competitions, darts competitions, fishing episodes, game viewing and ranging, they impact greatly to the economic sustainability of the country.

Recreation and sport are sides of the same coin, therefore, since farmers in A2 model farms have larger tracts of land, they can also venture into gaming (rearing wild animals) for tourism. Venturing into tourism is a lucrative business that generates income from locals and foreigners who want to spend their leisure time viewing nature.

\subsection{Effects of Sedentary Life}

A sedentary life style is defined by Tremblay et al (2015) as that life style independent of physical activity levels. They further alluded to the fact that sedentary behaviours are associated with increased risk of cardio-metabolic disease, all-cause mortality, and a variety of physiological and psychological problems. Health Matters, March 2014 Issue 14, advocates that most gestational diabetes patients can control their diabetes with exercise and diet. From this scientific discovery, this study recommends farmers to change their life style of not participating in sport and leisure to that of being physically active as sport and leisure has the power to burn the accumulated sugars and lactic acids and eventually vent-off emotions.

As newly resettled farmers are realising some profits from produces in tobacco, market-gardening and poultry farming for their first time, there is a possibility of them buying televisions, music gadgets and over-supply of western food stuff. From Tremblay et al (2015)'s 232 studies of 983,840 participants, television watching was the common measure of sedentary behaviour and body composition was the most common outcome measure. Qualitative analysis of all the studies revealed a dose-response relation between increased sedentary behaviour and unfavourable health outcomes. This danger from sedentary life-style might be true in newly resettled farmers as most of them are keen to possess modern home gadgets which they were unable to buy due to poverty when they were in poor lands. The end result is having idle and sick farming population which is unable to contribute significantly to the ZIMASSET's Food Security and Nutrition goal.

\subsection{Tenets of ZIMASSET and Sport Participation}

The Government of Zimbabwe, in pursuit of a new trajectory of accelerated economic growth and wealth creation has come up with a new plan code named Zimbabwe Agenda for Sustainable SocioEconomic Transformation (ZIM ASSET) in October 2013-December 2018. The major philosophies underpinning this plan are indigenization, empowerment and employment creation. The success of this plan is fuelled by various driving forces and the most indispensible one among others is the human resource. Therefore, this study views a healthy population as quite crucial in taking this plan to greater heights by motivating the farming population to embark upon a sport and recreation life-style which has much more free health benefits which transcend to economic benefits. One of the four strategic cluster that relates to farmers as their duty is Food Security and Nutrition, therefore, it is imperative to have the newly resettled farmers to be free from chronic diseases so as to partake actively in food production, that is why this study argues that since sport and recreation has the power to preserve good health of the people, farmers should be motivated to participate in sport and recreation as cheapest medicine as well as business. A healthy nation is an economically sound nation (Munroe, 2001). 


\subsection{Types of Sport and Recreation Activities and Strategies in Farming Areas}

The vast tracts of land that are found in these farming models provide opportunity to establish play fields for any sport and recreational activities for farmers given the expertise to do so. Games like soccer, netball, swimming, cricket, rugby, tennis, athletics to mention some, could be possible and what is required is the expertise to construct these pitches and right sport equipment.

Simple recreational games like chess and darts can be played indoors. Dick (1992) proposed the availing of trained staff and funding to start sport projects in communities. This vision augurs very well as it complements government efforts of initiating community sport projects like FIFA Goal Project and Community Sport Project and others. The major setback to this sport development initiative could be lack of financial support and inconsistency in policy enforcement when it comes to such farming population. The corporate world could be incorporated to direct their sponsorship and corporate responsibilities to develop communities sport facilities,(Hoye et al 2009). To create a culture of sport and recreation in a community, Lemke, a special adviser on Sport for development and Peace at the UNOSDP, (2013) advised all governments to develop meaningful and operational policy frameworks that include sport for their national and international development strategies.

\section{RESEARCH METHODOLOGY}

The study is a qualitative study that employed the case study as the ideal design that could concentrate on fewer selected farming communities that shared common set up and culture. This design enabled the researchers to have an in-depth study of the farming communities through several interaction platforms whilst in their natural vicinities so as to make exact conclusions of their perceptions, beliefs, attitudes and commitments. The researchers adopted this qualitative approach as it paved way for the use of interviews, open ended questionnaires and observations to solicit relevant information from participants to gain deeper insights into what their perceptions are on sports participation. This instrument triangulation method enabled the researchers to compare responses from participants and draw exact conclusions for the study (Creswell, 2007). To solicit adequate and relevant information from the stratified participants, the researchers distributed open ended questionnaires during gatherings of those farmers and collected the answered open ended questionnaires for analysis. The literate youth were given open ended questionnaires whilst other age groups were interviewed and observed. There was a $100 \%$ return rate on these open ended questionnaires. Households were visited and interviewed and observed during and after farm-work. It was an easy task to collect opinions, beliefs and arguments of the participants since the other researcher was a known resident and sport administrator among this farming population.

\section{Population And Sample}

The population of this study which were deemed necessary included farmers in A1 and those in A2 model farms only. The actual participants were selected using ecological sampling technique and stratified sampling technique. Each farm was taken as a different setting and different environment as these farms inherited different resources in terms of sport, recreational and learning facilities. The sample size had 75 participants who were stratified into different age groups, that is, school age group, youth age group and above youth age group. These age groups were considered on the basis that they have different sport appreciation and life aspirations.

\section{Discussion OF FINDINGS}

It emerged that $100 \%$ of the farmers sampled indicated that they desire to engage themselves in sport activities although they are haunted by the keenness to produce expected yields to prove their reason to be in the farms. The farming population was driven by greediness to increase their hacterage, that is why they annexed sport facilities into extra farming portions, for instance, soccer fields, netball fields, cricket, polo fields and recreational centres to grading shades. The general feeling by farmers was that they expect the youths to engage themselves in sport activities for entertainment, not for any health knowledge.

It was found out that the so called satellite schools have constructed play fields and during political campaigns farming communities use those fields for soccer and netball, and that has motivated most of these communities to love sport to some extent. Unfortunately, after the political campaigns and when the donated sports equipment is unusable it was observed that the communities seize to play and they concentrate on their farming activities and fail to repair the equipment or purchase their own. 
Interviewed players blamed this scenario saying it is a result of a growing culture among newly resettled communities who heavily rely on government donations for every development programme.

On knowledge of the benefits these farmers would get from sport and recreation participation, it emerged that the three strata of respondents had scanty knowledge and this probably made them not to be motivated to preserve existing sport facilities. The most affected population was the over 60 age group which was on the forefront of getting land and they do not appreciate sport as a right step towards diseases prevention. The second stratum, i.e. those in the range of 35 years to 59 years are highly obsessed by wanting to produce higher yields to pay school fees for their growing families and also want to utilise farming profits to sustain their family lives, otherwise it was because they left town job markets with the purpose of benefiting from farming as the only source of income, therefore, spending time on leisure activities could be regarded as worthless. The youthful age group of less than 35 years did appreciate the benefits of doing sport as they were seen playing mini-soccer and netball games on home-yards and grazing lands.

Interviewed youths even believed that sport makes them fit always, and could mention certain diseases by names which could be prevented through sport and exercise. Their appreciation of sport benefits could be because this age group includes the school-going boys and girls who are constantly told of the benefits of exercise by teachers and the literature and it also emerged that the motivating factor for participating in sport and exercise among the youth was that they want to emulate elite sport celebrities they see in mass media.

It was only this youth age group that has singled out fear of obesity as the reason of doing sport and exercise, unlike other age groups who expressed no knowledge of effects of sedentary life-style.

Various minds among the respondents have suggested some strategies that would see newly resettled farmers participate in sport and recreational life-style. Simple and inexpensive games like soccer, netball and athletics could be introduced in these farms by volunteer trainers including satellite school teachers as their Key Result Areas. The corporate world, as suggested by Steward et al (2004) in Hoye et al (2009), could be incorporated to sponsor sport clubs in farms and use the potential of sport to gather people and market their products, and that mind emerged commonly from various participants in this study.

\section{Conclusions}

From the findings in this study, the researchers took this stand point:

- The majority of farmers in models A1 and A2 know the social benefits of participating in sport and recreational activities, but are not aware of economic benefits accrued from this life-style.

- Sedentary life-style has negative socio-economic impact to the ZIMASSET blue-print theme (Food Security and Nutrition).

- Participation in sport and exercise is the cheapest panacea to lower health risks and makes farmcommunities gather and share farming expertise.

- The 60 years age group excludes itself from sport participation and expects the youth to engage in active sport.

- Donor syndrome bedevils self-sustenance among farmers in Zimbabwe in terms of sport development initiatives.

- There are several strategies to make the farming community engage in sport and recreational lifestyle which need to be taped up.

\section{RECOMMENDATIONS}

The study aligned the following recommendations which seek to motivate the farming populace to appreciate sport and recreation participation:

- The responsible Ministry of Sport, Arts and Culture in conjunction with Ministry of Health and Child Care, Ministry of Agriculture and Ministry of Youth should introduce sport committees that are funded to run sport and recreation activities in newly resettled farming communities. 
- Since politicians have realised the power of sport in their campaign rallies, they should establish sports clubs in farms which compete in their tournaments.

- Health and Economic development advocacies through sport should be launched in farm communities by non-governmental organizations and any other interested potential entities.

- Local governments should construct and rehabilitate more sport and recreation centres in farm communities to motivate farmers to engage in active sport and exercise.

\section{REFERENCES}

Ashton, A.J.K., Gerrard, B. and Hudson, R. (2003). Economic impact of national sport success: evidence from the London stock exchange, Applied Economics letters, 10(12) pp. 783-785.

Brown, J.S. (2010). Sport and Active leisure. Essex Pearson Education Ltd.

Dick, F.W. (1992). Sport Training Principles. London: Lepus Books.

Hoye, R,. Smith, A., Nicholson, M., Stewart. and Westerbeek, H. (2009). Sport Management. principles and applications. London Elsevier Ltd.

Luiz, J. and Fadal, R. (2010). An Economic Analysis of Sports Performance in Africa. Witwatersrand Business School.

Ministry of Health and Child Care (2014). Addressing the Social Determinants of Health. Health Matters. March 2014 Issue 14.

Mugari, A., and Masocha, V. (2015). Sport, an Empowering Force for Women: Reflection of Barriers to Participation. IJRHSS Vol 2, Issue 2. Pp45-52. SRYHWA Publications.

Munroe, M. (2001). The Purpose And Power of Women. New York.

Tremblay, M.S. LeBlanc, A.G, Kho, M.E. Saunders, T.J. Larouche, R. Colley, R.C. Goldfield, G. and Connor, G.S (2015). Systematic review of sedentary behaviour and health indicators in schoolaged children and youth. Pub Med.

UNICEF (2014). Ministry Manages Health Crisis. Harare.

\section{AUTHORS' BIOGRAPHY}

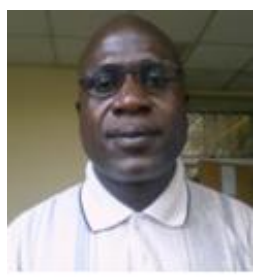

Abisha Mugari, is the Regional Program Coordinator and lecturer in the Department of Physical Education and Sport at the Zimbabwe Open University (ZOU) in Mashonaland East Region. He holds a Master of Education in Educational Management Degree from Midlands State University and a Bachelor of Science in Physical Education and Sport from ZOU. He has a certificate in Education from Seke Teachers` College, he has an International Certificate in module writing awarded by ZOU. He has published several articles in the field of Physical Education and Sport and is a member of various sport organisations.

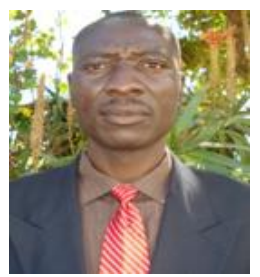

Richard BUKALIYA, is a Professor teaching at the Zimbabwe Open University in the Faculty of Arts and Education. He is the Regional Programme Coordinator in the Department of Teacher Development. His research interests include issues in Distance Education and Primary and Secondary education. The researcher has, to date, published several research articles in several international journals. He has presented papers at conferences locally and internationally. $\mathrm{He}$ is on the review boards of several international research journals which include the International Journal of Social Sciences and Education (IJSSE), The International Journal of Educational Research (JER), Greener Journals and the Global Research Journal of Education. 